\title{
Computer Analysis of Acinetobacter lwoffii (Moraxella lwoffii) and Acinetobacter anitratus (Moraxella glucidolytica) Strains
}

\author{
By M. PINTÉR AND IRENE BENDE \\ Department of Bacteriology, County Hospital, Gyula, Hungary
}

(Accepted for publication 2 September 1966)

SUMMARY

\begin{abstract}
Adansonian analysis of 31 Acinetobacter lwoffi and 8 A. anitratus strains is described. The mean S-value was 81.9 and $87.3 \%$ for groups $A$. lwoffii and $A$. anitratus, respectively. The intergroup value was $71.9 \%$. The computer distinguished well the Alcaligenes faecalis strains from the former two species. According to the computer analysis, Bordetellabronchiseptica is closely related to A. faecalis. Pseudomonas aeruginosa and Aeromonas liquefaciens link with the former groups at a much lower level.
\end{abstract}

\section{INTRODUCTION}

The systematics of Gram-negative non-fermenting bacteria has been fairly uncertain. Although numerous data have been available in the literature on the taxonomy of the genera Pseudomonas, Alcaligenes, Moraxella, Achromobacter and Flavobacterium, many questions have been left unanswered. Much dispute has arisen about the systematic position and nomenclature of the Gram-negative coccobacillary microorganisms classified by various authors in the genera Moraxella, Mima, Achromobacter, Acinetobacter and Cytophaga, or designated 'Bacterium anitratum'. The available biochemical, serological, and morphological data are too scanty to permit reliable classification. A new basis for the systematics of these genera is offered by Adansonian analysis, applied first to bacteria by Sneath (1957). During recent years many valuable results have been obtained in bacterial systematics by computer analysis. As to the Gram-negative non-fermenting bacteria, most reports have been published on the computer analysis of Pseudomonas species (Colwell \& Liston, 1961; Rhodes, 1961). Information has been relatively scanty about other non-fermenting bacteria. Thornley (1961) succeeded in separating 'Bacterium anitratum', Mima and Alcaligenes faecalis strains into distinct groups. In extensive studies involving numerous bacterial species, Beers, Fisher, Megraw \& Lockhart (1962), and Focht \& Lockhart (1965) found that on numerical analysis, the biochemically inactive non-fermenting bacteria appeared to form a distinct group and to link with other Gram-negative bacteria only at a low level.

The present work was done to examine the relations in 'polythetic' numerical analysis of bacterial strains isolated from clinical material and identified 'monothetically'. Mainly Acinetobacter lwoffii and Acinetobacter anitratus strains were studied, other Gram-negative non-fermenting bacteria (Alcaligenes faecalis, Bordetella bronchiseptica, Pseudomonas aeruginosa, one Aeromonas liquefaciens strain) being used for comparison. 


\section{METHODS}

Organisms. Out of a total of 47 strains examined, 39 were isolated in our laboratory from clinical material (urine, blood, bile, sputum, pus). Identification was done mostly by means of the diagnostic tables of Cowan \& Steel (1965). Four strains were kindly supplied by Dr S. T. Cowan (from the National Collection of Type Cultures, London, NCTC), and a further 4 strains from the collection of Statens Seruminstitut, Copenhagen, through the courtesy of Dr H. Lautrop. Our serial numbers, the designations and origins of the strains are listed below.

Nos. 1-28. Acinetobacter lwoffii. Our isolates.

No. 29. A. lwoffii, NCTC 5866.

Nos. 30, 31. A. lwoffii, Statents Seruminstitut. Original designation: 'Bacterium anitratum' type B, A3 and A 14 .

Nos. 32-36. A. anitratus. Our isolates.

No. 37. A. anitratus, NCTC 7844.

Nos. 38, 39. A anitratus, Statens Seruminstitut. Original designation: 'Bacterium anitratum' type $\mathrm{A}, \mathrm{A} 1$ and $\mathrm{A} 4$.

Nos. 40, 41. Alcaligenes faecalis. Our isolates.

No. 42. A. faecalis, NCTC 415.

No. 43. Bordetella bronchiseptica, NCTC 8761.

Nos. 44-46. Pseudomonas aeruginosa. Our isolates.

No. 47. Aeromonas liquefaciens. Our isolate.

Cultivation of organisms and determination of characters. The strains were maintained on nutrient agar slopes. Before examination, the strains were streaked on nutrient agar plates. A single isolated colony was transferred to a nutrient agar slope and after incubation for $24 \mathrm{hr}$. the cultures were washed off with saline. This suspension was used as starting material. The incubation temperature used was always $25^{\circ}$. The tests applied and the characters found are shown in Table 1. During coding, the 79 characters listed in the table yielded 98 character states on the basis of secondary data. For biological and biochemical assay we used the procedures recommended by Cowan \& Steel (1965).

Computer analysis. Programming and calculations were performed by the Computer Centre of the Hungarian Academy of Sciences (Budapest). The programmes were written by L. Ferenczy and computed on a Ural (USSR) type computer. The experimental data were coded and tabulated by two different methods and calculated in parallel. The following two coding systems were used:

Coding system 1. Data were tabulated with the designations,+- , or n.c. (not counted). On the basis of these data, and by appropriate programming, the computer gave the values of matching coefficient (affinity index) for each pair of strains (Sokal \& Michener, 1958). Both the positive and negative properties were included in this analysis. Quantitative properties were coded by the additive method. Properties giving uniform responses with all strains were excluded from the analysis.

Coding system 2. Data were coded by the four-symbol (A, B, C, D) system introduced by Lockhart \& Hartman (1963). The computer indicated similarity when two symbols were identical; in all other cases it indicated dissimilarity. In this sytem, too, 'negative' properties were also included in the evaluation under the appropriate symbol.

After the determination of the S-values the strains were grouped by the highest link- 
sorting method. Highest link sorting was made with several starting pairs and served as the basis for forming groups. After clustering, mean intra-group and inter-group values were computed.

Table 1. Properties of test organisms included in the numerical analysis

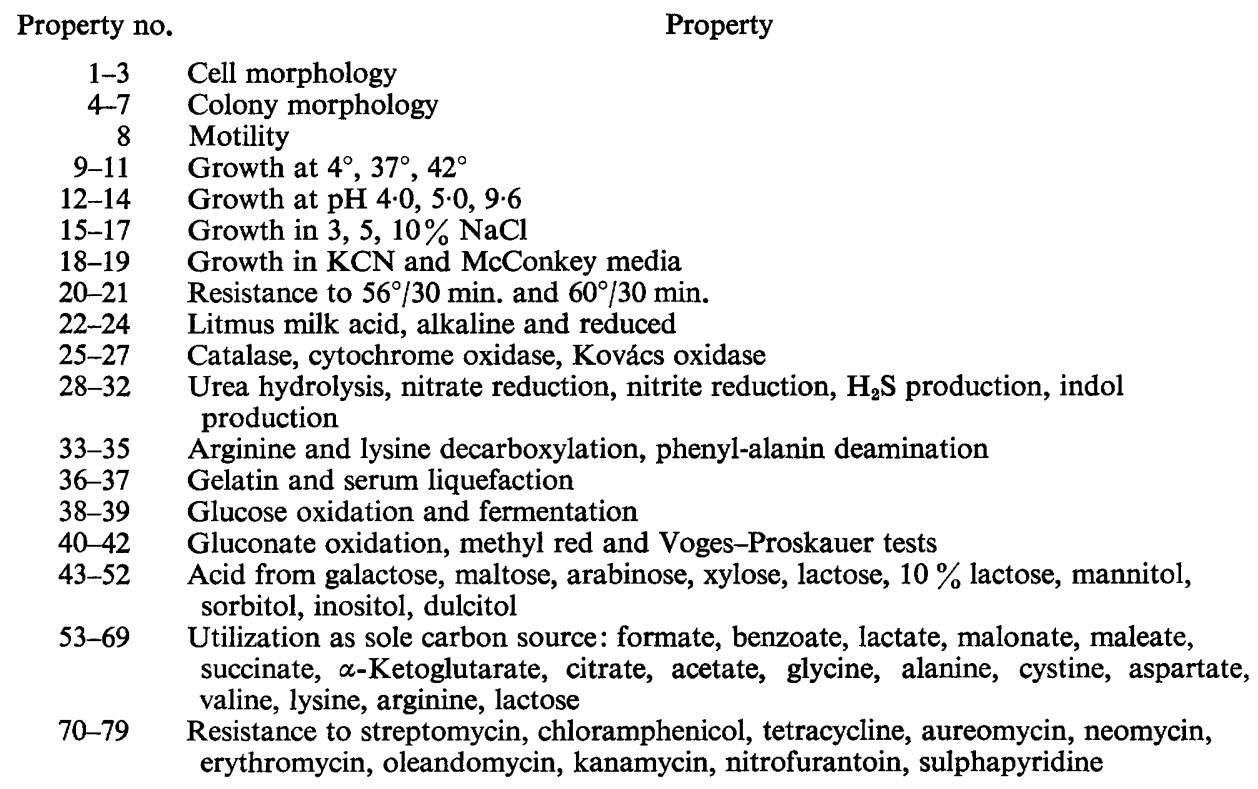

\section{Table 2. Intra-group and inter-group $S$-values}

The upper values in each pair are from coding method 1 ; The lower values from coding method 2 .

Species

\begin{tabular}{|c|c|c|c|c|c|}
\hline Acinetobacter lwoffii & $\begin{array}{l}82 \cdot 4 \\
81.9\end{array}$ & - & - & - & $\overline{-}$ \\
\hline A. anitratus & $\begin{array}{l}70 \cdot 9 \\
71 \cdot 9\end{array}$ & $\begin{array}{l}84 \cdot 7 \\
87 \cdot 3\end{array}$ & - & - & 二 \\
\hline $\begin{array}{l}\text { Alcaligenes faecalis, } \\
\text { Bordetella bronchiseptica }\end{array}$ & $\begin{array}{l}68 \cdot 0 \\
69 \cdot 5\end{array}$ & $\begin{array}{l}66 \cdot 0 \\
67 \cdot 1\end{array}$ & $\begin{array}{l}77 \cdot 0 \\
78 \cdot 1\end{array}$ & - & - \\
\hline Pseudomonas aeruginosa & $\begin{array}{l}55 \cdot 1 \\
54 \cdot 3\end{array}$ & $\begin{array}{l}67 \cdot 8 \\
66 \cdot 0\end{array}$ & $\begin{array}{l}67 \cdot 5 \\
68 \cdot 8\end{array}$ & $\begin{array}{l}82 \cdot 0 \\
83 \cdot 0\end{array}$ & - \\
\hline Aeromonas liquefaciens & $\begin{array}{c}60 \cdot 0 \\
56 \cdot 7 \\
\text { A. lwoffii }\end{array}$ & $\begin{array}{c}59 \cdot 5 \\
56 \cdot 7 \\
\text { A. anitratus } \\
\quad B\end{array}$ & $\begin{array}{l}\quad 62 \cdot 0 \\
\quad 61 \cdot 7 \\
\text { A. faecalis, } \quad \text { I } \\
\text { bronchiseptica }\end{array}$ & $\begin{array}{c}\quad 60 \cdot 5 \\
59 \cdot 0 \\
P . \text { aeruginosa } \\
a\end{array}$ & $\begin{array}{c}100 \cdot 0 \\
100 \cdot 0 \\
A . \\
\text { liquefaciens }\end{array}$ \\
\hline
\end{tabular}

In Table 2 are shown the average intra-group and inter-group S-values obtained by two methods of coding. The results obtained by two methods do not differ significantly. In every case, intra-group S-values were higher than $75 \%$, representing, we believe, the species level, whereas the inter-group values were lower. Considering the mean values, linking at the highest level occurs between Acinetobacter lwoffi $i$ and $A$. anitratus; with $A$. lwoffii is linked the Alcaligenes group and with that the group Pseudomonas aeruginosa. 
The dendrogram presented in Fig. 1 has been derived from highest link sorting based on the second coding system. The above groups are well separated by this method; links occur, at a higher level. The linking of Acinetobacter anitratus strains to each other ceases at the $90 \%$ level; that of $A$. lwoffi i strains to each other at $84.7 \%$. The highest link between the two groups is at $79.8 \%$.

The three Alcaligenes faecalis strains and the Bordetella bronchiseptica strain formed a uniform group in all phases of analysis. They link with the Acinetobacter lwoffii at a

\begin{tabular}{|c|c|c|c|c|c|c|}
\hline \multicolumn{7}{|c|}{$\%$ Similarity } \\
\hline 65 & 70 & 75 & $80 \quad 85$ & 90 & 95 & 100 \\
\hline
\end{tabular}

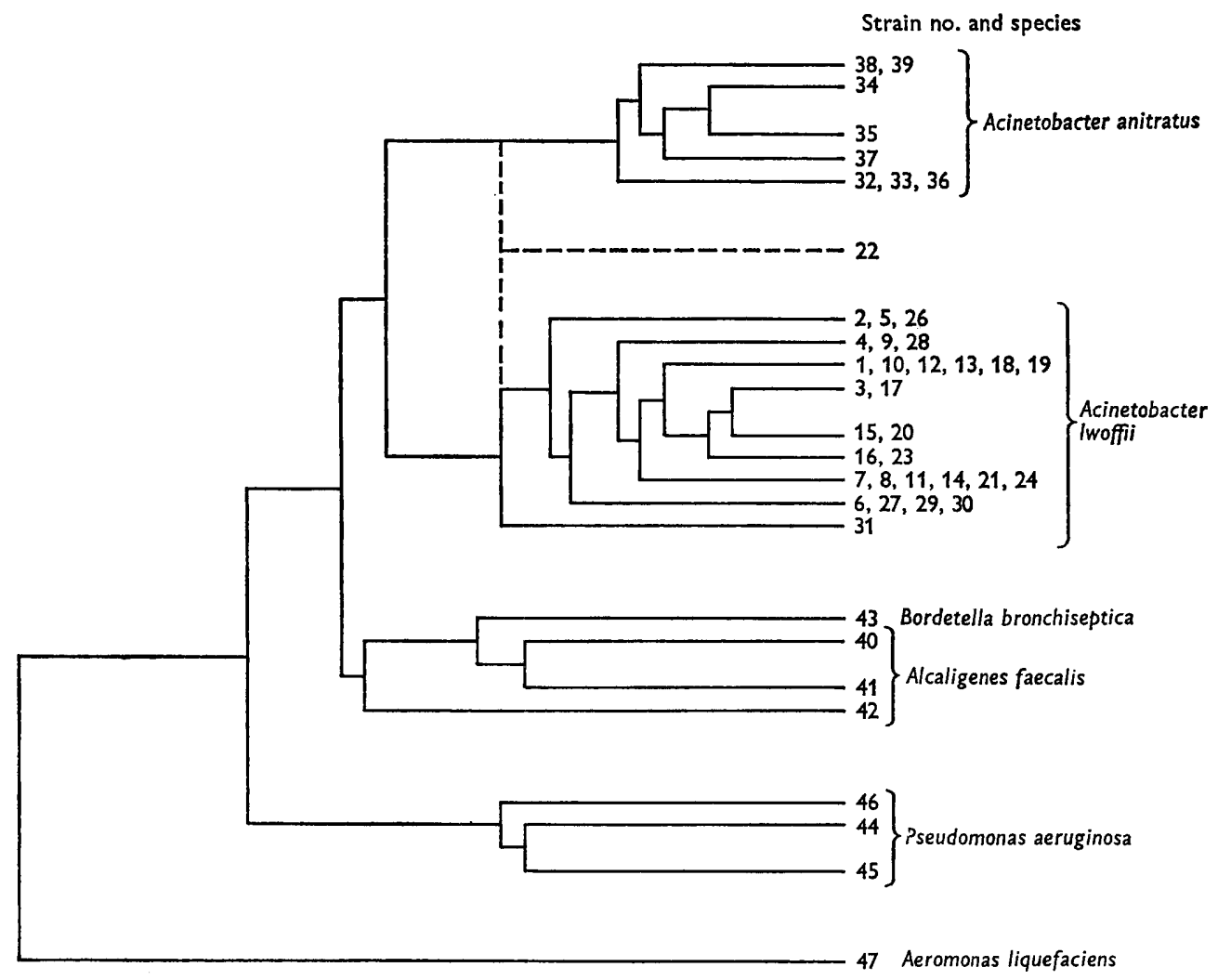

Fig. 1. Similarity relationships among the organisms as shown by coding method 2.

relatively high S-value (78.6\%), but the much lower inter-group mean S-value shows them to be significantly different from $A$. lwoffii. The $B$. bronchiseptica strain was very similar to the two $A$. faecalis strains isolated in this laboratory, but the $A$. faecalis NCTH 415 strain showed lower S-values, in comparison with the other three.

Difficulties were encountered in the classification of one strain, serial no. 22, labelled as Acinetobacter lwoffii. This linked at nearly identically high levels with both the $A$. lwoffii and $A$. anitratus groups. Also, the average S-values between strain no. 22 and these two groups were nearly the same.

As expected, the Pseudomonas aeruginosa strains were well separated from the abovementioned groups, and still lower S-values were obtained with Aeromonas liquefaciens. 


\section{DISCUSSION}

The systematic position of Gram-negative non-fermenting bacteria has been discussed in numerous recent publications. A reliable classification of these organisms is rendered difficult by the low number of their biochemical reactions as well as by the uncertainty of serological tests. Their identifications is usually restricted to a few procedures (examination for flagella, mode of glucose decomposition, oxidase reaction, nitrate reduction, urease production, etc). The monothetic method of identification, however, involves always the risk of obtaining erroneous results. In the case of Acinetobacter lwoffii and A. anitratus, the polythetic analysis reported in the present paper has proved the validity of these two species. Nevertheless, no perfectly sharp borders could be drawn between the two species. This observation is in good accord with the data available on the antigenic structure of the same organisms. Common antigens have been demonstrated in the strains of $A$. lwoffii (Mima) and A. anitratus (Herellea) by Brodie \& Henderson (1964) and Mitchell \& Burrel (1964).

The relatively uniform features revealed by the analysis of Alcaligenes faecalis and Bordetella bronchiseptica support the suggestion of Steel \& Cowan (1964) that $B$. bronchiseptica should be placed in the genus Alcaligenes. An attempt was made to compare a strain of B. parapertussis NCTC 5952 with the strains Acinetobacter lwoffii. The conditions for cultivation and the nutritional requirements of these strains were, however, so different as to render reliable comparison impossible. Thus we are not in a position either to agree or to disagree with the suggestion by Steel \& Cowan (1964) to classify $B$. parapertussis in the genus Acinetobacter.

The results of Adansonian analysis depends on the methods of coding and computing. This is particularly true for Gram-negative non-fermenting bacteria characterized by a relatively poor range of biochemical activities. It is believed, however, that further progress requires not so much the application of new methods of computing, as the further extension and improvement of bacteriological methods.

The authors are indebted to Drs S. T. Cowan and H. Lautrop for having kindly supplied the type strains. Thanks are due to Mr J. Szelezsán and Mr L. Ferenczy for having done the mathematical part of this work.

\section{REFERENCES}

Beers, R. J., Fisher, J., Megraw, S. \& Lockhart, W. R. (1962). A comparison of methods for computer taxonomy. J. gen. Microbiol. 28, 641.

Brodie, J. \& Henderson, A. (1964). Further observations on Mima polymorpha and Achromobacter (Bacterium) anitratum. J. clin. Path. 17, 513.

Colwell, R. R. \& Liston, J. (1961). Taxonomic relationship among the pseudomonads. J. Bact.82, 1.

CowAN, S. T. \& SteEl, K. J. (1965). Manuel for the Identification of Medical Bacteria. Cambridge: University Press.

Focht, D. D. \& Lockhart, W. R. (1965). Numerical survey of some bacterial taxa. J. Bact. 90, 1314.

Lockhart, W. R. \& HARTMan, P. A. (1963). Formation of monothetic groups in quantitative bacterial taxonomy. J. Bact. 85, 68 .

Mrtchell, P. D. \& Burrel, R. G. (1964). Serology of the Mima-Herellea group and the genus Moraxella. J. Bact. 87, 900.

RHODES, M. E. (1961). The characterization of Pseudomonas fluorescens with the aid of an electronic computer. J. gen. Microbiol. 25, 331. 
SNEATH, P. H. A. (1957). The application of computers to taxonomy. J. gen. Microbiol. 17, 201.

SOKAL, R. R. \& MICHENER, C. D. (1958). A statistical method for evaluating systematic relationships. Kansas Univ. Sci. Bull. 38, 1409.

Steel, K. J. \& Cowan, S. T. (1964). Le rattachement de Bacterium anitratum, Moraxella lwoffii, Bacillus mallei et Haemophilus parapertussis au genre Acinétobacter Brisou et Prévot. Ann. Inst. Pasteur 106, 479.

THORNLeY, M. J. (1961). Cited by P. H. A. Sneath (1964). A. Rev. Microbiol. 18, 335. 